\title{
Antenatal Thyroid Function Does Not Increase Risk of Gestational Diabetes Mellitus in a Multi-Ethnic Pregnancy Cohort
}

\author{
Christopher Alan Muir', Ashish Munsif ${ }^{1}$, Kenrick Blaker ${ }^{1}$, Yvonne Feng", \\ Mario D'Souza ${ }^{3}$ and Shailja Tewari ${ }^{2}$ \\ Department of Endocrinology, St. Vincent's Hospital ${ }^{1}$, Division of Medicine, The Canterbury Hospital ${ }^{2}$, Clinical Research Centre, \\ Sydney Local Health District, Sydney, NSW, Australia
}

\begin{abstract}
Background and Objectives: Subclinical hypothyroidism in pregnancy has been inconsistently associated with an increased risk of developing gestational diabetes mellitus (GDM). Materials and Methods: We retrospectively examined whether an antenatal thyroid stimulating hormone (TSH) level $\geq 2.5 \mathrm{mlU} / \mathrm{L}$ was associated with increased risk of GDM in 1147 pregnant women residing in a multi-ethnic suburban area of Sydney, Australia. Results: Despite a high prevalence of GDM and hypothyroidism in our study, women with antenatal TSH concentrations $\geq 2.5 \mathrm{mlU} / \mathrm{L}$ were not at increased risk for development of gestational diabetes. Traditional risk factors for GDM, such as maternal body mass index, ethnicity, previous GDM pregnancy and family history of type 2 diabetes were significant predictors of incident GDM on multivariable analyses. Conclusion: Mild elevations in antenatal TSH concentration did not significantly increase risk of incident GDM compared to healthy euthyroid women.
\end{abstract}

Key Words: Gestational diabetes, Hypothyroidism, Pregnancy, Maternal health, Antenatal screening

\section{Introduction}

Thyroid disorders occur in 3-5\% of pregnancies, although some reports estimate the combined prevalence of overt and subclinical hypothyroidism could be as high as $15 \%{ }^{1)}$ Hypothyroidism in pregnancy is clinically significant and has been associated with a range of adverse obstetric and fetal health outcomes including pregnancy loss, premature labour and impaired neurocognitive development of the newborn. ${ }^{2,3)}$ The incidence of gestational diabetes mellitus (GDM) may also increase in the setting of reduced thyroid function, although published data are inconsistent with some reporting a significant association and others finding no apparent relationship. ${ }^{4-11)}$ Given the strong association of increased pregnancy-related and perinatal morbidity, the role of universal screening for diabetes in pregnancy is well established. However, the efficacy of routine screening for thyroid dysfunction remains controversial and is not currently recommended. Predictive value of thyroid function in identifying women at increased risk of GDM would add merit to the argument for universal screening of thyroid function during pregnancy.

Received January 30, 2020 / Revised March 24, 2020 / Accepted March 30, 2020

Correspondence: Christopher Alan Muir, MBBS, FRACP, Department of Endocrinology, St. Vincent's Hospital Darlinghurst, Sydney, NSW 2010, Australia

Tel: 6l-283821lll, Fax: 61-283823179, E-mail: cmui7357@uni.sydney.edu.au

Copyright (c) the Korean Thyroid Association. All rights reserved.

(1) (\$) This is an open-access article distributed under the terms of the Creative Commons Attribution Non-Commercial License (http://creative(c) 1 commons.org/licenses/by-nc/4.0/), which permits unrestricted non-commercial use, distribution, and reproduction in any medium, provided the original work is properly cited. 


\section{Materials and Methods}

We retrospectively studied outcomes in consecutive singleton pregnancies managed via a hospital antenatal clinic and delivered in a single centre between January 1, 2016 and December 31, 2016. The primary study aim was to investigate whether subclinical hypothyroidism in pregnancy increased the risk of developing GDM independent of other known risk factors. Thyroid screening was performed at the discretion of the referring general practitioner prior to referral to the antenatal care clinic. Women with a first trimester thyroid stimulating hormone (TSH) level greater than $2.5 \mathrm{mIU} / \mathrm{L}$ were considered to have subclinical hypothyroidism and were treated with levothyroxine as per the 2011 American Thyroid Association guidelines in use at that time under the supervision of an endocrinologist. ${ }^{12)}$ For the majority of women, first trimester TSH was measured at 4-6 weeks gestation, however TSH values recorded up to 13 weeks gestation were considered adequate for assessment of first trimester thyroid function. Thyroid function tests were repeated at the beginning of each trimester to ensure a TSH of less than $2.5 \mathrm{mIU} / \mathrm{L}$ in the first trimester, and less than $3.0 \mathrm{mIU} / \mathrm{L}$ thereafter. Thyroid hormone levels and thyroid peroxidase (TPO) autoantibody titres were not routinely measured in our cohort. All women underwent screening for GDM via a 75-gram oral glucose tolerance test between 24-28 weeks gestation. All women diagnosed with GDM were routinely reviewed at diagnosis by a credentialed dietician and given directed dietary advice concentrating on carbohydrate estimation and portioning. Additional visits were discretionary and based on endocrinologist or diabetes educator assessed clinical need. Women without GDM were not reviewed by a dietician.

Data are expressed as mean \pm standard deviation (SD) or as a frequency and percentage for categorical variables. Baseline characteristics were compared using independent samples t-test for numeric outcome variables and Pearson's chi-square test for categorical outcome variables. Logistic regression analyses were performed to calculate odds ratios and 95\% confidence intervals estimating the likelihood of develop-

Table 1. Baseline characteristics of the study population by antenatal TSH concentration

\begin{tabular}{|c|c|c|c|}
\hline \multirow{2}{*}{ Parameter } & & \multicolumn{2}{|c|}{ TSH } \\
\hline & & $\geq 2.5 \mathrm{mIU} / \mathrm{L} \quad(\mathrm{n}=183)$ & $<2.5 \mathrm{mIU} / \mathrm{L}(\mathrm{n}=964)$ \\
\hline Current GDM & $\mathrm{n}(\%)$ & $54(29.5)$ & $266(27.6)$ \\
\hline 75-gram OGTT $(\mathrm{mmol} / \mathrm{L})$ & mean (SD) & & \\
\hline Fasting & & $4.5(0.5)$ & $4.5(0.6)$ \\
\hline 1-hour & & $8.0(2.0)$ & $7.9(2.0)$ \\
\hline 2-hour & & $6.5(1.6)$ & $6.4(1.7)$ \\
\hline Age (year) & mean (SD) & $29.8(4.9)$ & $30.3(5.1)$ \\
\hline Ethnicity & n $(\%)$ & & \\
\hline Caucasian & & $18(9.8)$ & $146(15.1)$ \\
\hline Asian & & $29(15.8)$ & $223(23.1)$ \\
\hline Indian subcontinent & & $101(55.2)$ & $299(31.0)$ \\
\hline Middle Eastern & & $30(16.4)$ & $227(23.5)$ \\
\hline Other & & $5(2.7)$ & $69(7.2)$ \\
\hline Antenatal BMI $\left(\mathrm{kg} / \mathrm{m}^{2}\right)$ & mean $(S D)$ & $24.6(4.7)$ & $25.2(5.2)$ \\
\hline Nulliparous & $\mathrm{n}(\%)$ & $53(29.0)$ & $282(29.3)$ \\
\hline Smoking during pregnancy & $\mathrm{n}(\%)$ & $3(1.6)$ & $40(4.1)$ \\
\hline Previous GDM & n (\%) & $24(13.1)$ & $94(9.8)$ \\
\hline Family history of T2DM & n $(\%)$ & $79(43.2)$ & $338(35.1)$ \\
\hline $\mathrm{TSH}(\mathrm{mIU} / \mathrm{L})$ & median (IQR) & $3.3(2.8-4.2)$ & $1.2(0.8-1.7)$ \\
\hline 25-hydroxyvitamin D (nmol/L) & mean (SD) & $46(20)$ & $47(22)$ \\
\hline
\end{tabular}

GDM: gestational diabetes mellitus, IQR: interquartile range, OGTT: oral glucose tolerance test, SD: standard deviation, T2DM: type 2 diabetes mellitus, TSH: thyroid stimulating hormone 
ing GDM. Antenatal thyroid function categorised as TSH above or below $2.5 \mathrm{mIU} / \mathrm{L}$ was the key variable of interest, and as such was included a priori in all analyses. All statistical tests were 2-tailed with the significance level set at $p=0.05$. Statistical analyses were conducted using SAS version 9.3 (SAS Institute Inc.). Ethics approval was granted by the Sydney Local Health District human research and ethics committee (LNR/17/RPAH/382).

\section{Results}

In total, 1147 singleton pregnancies underwent screening for GDM and thyroid dysfunction and delivered in hospital over the 1-year study period. Mean age was $30.4( \pm 5.0)$ years and $29.2 \%$ of women were nulliparous. Subclinical hypothyroidism in pregnancy (TSH $\geq 2.5 \mathrm{mIU} / \mathrm{L}$ ) was present in 183 (15.9\%) subjects with a median TSH value of $3.3 \mathrm{mIU} / \mathrm{L}$ (interquartile range, 2.8-4.2). Baseline demographic characteristics of participants by antenatal thyroid status are presented in Table 1. The study cohort was multi-ethnic, with over one third of participants originating from the Indian subcontinent and approximately one fifth from the Middle East and North Africa. Three hundred twenty women (27.9\%) developed GDM over the study period. Treatment consisted of insulin for 164 women (51.1\%), with the remainder managed using diet and lifestyle modification. Metformin was prescribed as part of GDM treatment in 42 women (13.2\%), predominately as co-therapy with insulin.

In univariate analyses, significant associations with GDM were observed for patient age, ethnicity, body mass index (BMI), vitamin D level, past GDM, and family history of type 2 diabetes mellitus (T2DM). Multivariate analysis of risk factors for developing GDM are presented in Table 2. We found no association between antenatal TSH values $\geq 2.5 \mathrm{mIU} / \mathrm{L}$ and subsequent risk of developing GDM compared to euthyroid controls. Ethnicity remained a strong predictor of GDM, with women from an Indian background at over 4-fold increased risk relative to their Caucasian counterparts. Asian ethnicity also conferred increased risk. Obesity significantly increased risk, particularly when antenatal BMI was greater than $35 \mathrm{~kg} / \mathrm{m}^{2}$ although there was a stepwise increase in risk with progressive increase in body mass indices above 20 $\mathrm{kg} / \mathrm{m}^{2}$. Other significant predictors of GDM on multivariate testing included past history of GDM and family history of type 2 diabetes mellitus in a first degree relative. Age did not significantly influence GDM risk, although there was a trend towards increased risk in women over age 35 years.

Following the 2017 update of the American Thyroid Association guidelines, the TSH threshold for treatment of hypothyroidism in pregnancy was modified to $\geq 2.5 \mathrm{mIU} / \mathrm{L}$ in TPO antibody positive women and $\geq 4.0$

Table 2. Antenatal factors and their association with risk of gestational diabetes mellitus in a pregnancy cohort

\begin{tabular}{|c|c|c|}
\hline Parameter & OR $(95 \% \mathrm{Cl})$ & $p$-value \\
\hline Age (year) & & 0.073 \\
\hline$<25$ & 1.00 & \\
\hline $25-30$ & $1.28(0.76-2.16)$ & \\
\hline $31-35$ & $1.60(0.95-2.70)$ & \\
\hline$>35$ & $2.00(1.12-3.56)$ & \\
\hline Ethnicity & & $<0.001$ \\
\hline Caucasian & 1.00 & \\
\hline Asian & $3.32(1.78-6.19)$ & \\
\hline Indian subcontinent & $4.46(2.46-8.08)$ & \\
\hline Middle Eastern & $1.40(0.75-2.61)$ & \\
\hline Other & $0.84(0.27-2.52)$ & \\
\hline Antenatal BMI $\left(\mathrm{kg} / \mathrm{m}^{2}\right)$ & & $<0.001$ \\
\hline$<20.0$ & 1.00 & \\
\hline $20.1-25.0$ & $1.32(0.78-2.22)$ & \\
\hline $25.1-30.0$ & $2.62(1.50-4.57)$ & \\
\hline $30.1-35.0$ & $3.34(1.69-6.60)$ & \\
\hline$>35.0$ & $5.22(2.29-11.9)$ & \\
\hline Previous GDM & & $<0.001$ \\
\hline No & 1.00 & \\
\hline Yes & $4.17(2.59-6.73)$ & \\
\hline Family history of T2DM & & 0.026 \\
\hline No & 1.00 & \\
\hline Yes & $1.45(1.05-2.01)$ & \\
\hline $\mathrm{TSH}(\geq 2.5 \mathrm{mIU} / \mathrm{L})$ & & 0.684 \\
\hline No & 1.00 & \\
\hline Yes & $0.75(0.48-1.16)$ & \\
\hline $\begin{array}{l}\text { 25-hydroxyvitamin D } \\
(\mathrm{nmol} / \mathrm{L})\end{array}$ & & 0.192 \\
\hline$>60$ & 1.00 & \\
\hline $30-60$ & $1.02(0.63-1.65)$ & \\
\hline$<30$ & $1.16(0.78-1.74)$ & \\
\hline
\end{tabular}

BMI: body mass index, $\mathrm{Cl}$ : confidence interval, GDM: gestational diabetes mellitus, OR: odds ratio, T2DM: type 2 diabetes mellitus, TSH: thyroid stimulating hormone 
$\mathrm{mIU} / \mathrm{L}$ in TPO antibody negative women. ${ }^{13)}$ Unfortunately, we did not measure TPO-antibody titres, and could not further stratify based on TPO positivity. In our cohort, 51 women (4.4\%) had antenatal TSH values $\geq 4.0$ $\mathrm{mIU} / \mathrm{L}$. An exploratory analysis using the higher TSH cut-off of $4.0 \mathrm{mIU} / \mathrm{L}$ also failed to predict onset of gestational diabetes mellitus.

\section{Discussion}

We present a retrospective analysis of subclinical hypothyroidism in a pregnancy cohort and its effect on the development of GDM during that same pregnancy. In our cohort of 1147 patients, we failed to show a significant relationship despite a high prevalence of gestational diabetes (27.9\%) and hypothyroidism as defined by TSH $\geq 2.5 \mathrm{mIU} / \mathrm{L}$ (15.9\%). Although thyroid function was not predictive of GDM onset, traditional risk factors such as ethnicity, pre-pregnancy BMI, past GDM and family history of T2DM significantly increased risk for development of GDM in the current pregnancy.

Normal pregnancy results in significant changes to thyroid hormone production and metabolism. Thyroid hormones have important effects on glucose homeostasis including regulation of hepatic gluconeogenesis, intestinal glucose uptake and peripheral glucose utilisation. ${ }^{14)}$ They may also influence glucose levels via modulatory effects on circulating insulin and counter-regulatory hormones. ${ }^{15)}$ Despite biological plausibility, it remains unclear as to whether there is a significant effect of mild hypothyroidism on glucose metabolism in the setting of pregnancy. To date, several studies have shown an increase in the prevalence of GDM associated with mild elevations in antenatal TSH concentation. ${ }^{4,5,16,17)}$ Where measured, the effect appears to be accentuated by the presence of a TPO antibody, with these women at 2-4 times increased risk of GDM compared to those with subclinical hypothyroidism and negative TPO antibodies. ${ }^{4,17)}$ However, multiple other studies have failed to show a significant relationship between antenatal TSH and GDM. ${ }^{6-11,18,19)}$ Therefore, at present it remains unclear whether TSH elevations in early pregnancy are associated with in- creased risk of GDM.

In the non-pregnant state, TSH is a reliable indicator of thyroid function, but in pregnancy maternal hCG activates the TSH receptor and TSH levels below the lower reference interval may be observed in up to $15 \%$ of healthy women. ${ }^{13)}$ As such, the association of other indicators of thyroid function on risk of GDM have been studied, including isolated hypothyroxinaemia, FT3 concentration and elevated FT3:FT4 ratio. ${ }^{11,18,19)}$ Conflicting data also exist for each of these markers, and as with TSH their predictive value for estimating risk of GDM remains questionable. ${ }^{4,8)}$

Different to our study, the published literature has predominately examined small sample populations or Caucasian and Hispanic women with relatively low incidence rates of gestational diabetes and thyroid dysfunction. Our data examined the association of TSH and GDM in an ethnically diverse population with a high prevalence of gestational diabetes, increasing generalisability of the findings. Strengths of our observational study include the large cohort size and inclusion of women from multiple ethnic backgrounds. Prevalence and absolute incidence rates of subclinical hypothyroidism and GDM were substantially higher in our cohort relative to those of other studies examining the thyroid-GDM relationship. Limitations of our study relate to its retrospective design. In our study, women with a TSH value of $>2.5 \mathrm{mIU} / \mathrm{L}$ received treatment with thyroxine to maintain TSH $<2.5 \mathrm{mIU} / \mathrm{L}$ in the first trimester, and $<3.0 \mathrm{mIU} / \mathrm{L}$ thereafter. It is possible that early identification and treatment of mild hypothyroidism in pregnancy may have negated any adverse effect low thyroid function may have on risk for gestational diabetes. Finally, serum thyroxine concentrations and TPO-antibody titres were not measured, and as such the relationship between GDM and hypothyroxinaemia or thyroid autoimmunity could not be explored. As stated previously, the TSH threshold for treatment was changed to $>4.0 \mathrm{mIU} / \mathrm{L}$ in 2017 American Thyroid Association guidelines. ${ }^{13)}$ We attempted to control for this through exploratory analyses of women with TSH concentrations $>4.0 \mathrm{mIU} / \mathrm{L}$ and of women with hypothyroidism predating the current pregnancy (on assumption they would be more 
likely to have positive TPO-antibodies). Neither analysis significantly influenced study results.

In conclusion, our results failed to show a significant relationship between modest elevations in serum TSH concentration and risk for development of GDM. These data are in keeping with the majority of published studies in this area, but large prospective studies are required to verify these findings which would have significant implications for the role of thyroid screening in pregnancy.

\section{Author Contributions Statement}

$\mathrm{CM}$ designed the study, collected data, wrote initial manuscript and was involved in all revisions. AM, KB, \& YF collected data and were involved with all manuscript revisions. MD developed the statistical analysis plan and performed statistical analyses. ST conceptualised the study and was involved with all manuscript revisions.

\section{Conflicts of Interest}

CM, AM, KB, YF, MD, \& ST do not have a financial relationship with a commercial entity that has an interest in the subject of the presented manuscript or other conflicts of interest to disclose. No specific funding was provided for this research. It was a clinical audit performed during employment by the Sydney Local Health District, NSW Health.

\section{Orcid}

Christopher Alan Muir: https://orcid.org/0000-0002-1430-0499

Ashish Munsif: https://orcid.org/0000-0001-6122-0996

Kenrick Blaker: https://orcid.org/0000-0002-9923-2594

Yvonne Feng: https://orcid.org/0000-0002-3048-147X

Mario D'Souza: https://orcid.org/0000-0001-5203-0808

Shailja Tewari: https://orcid.org/0000-0002-0784-4199

\section{References}

1) Blatt AJ, Nakamoto JM, Kaufman HW. National status of testing for hypothyroidism during pregnancy and postpartum. J Clin Endocrinol Metab 2012;97(3):777-84.
2) Leung AS, Millar LK, Koonings PP, Montoro M, Mestman JH. Perinatal outcome in hypothyroid pregnancies. Obstet Gynecol 1993;81(3):349-53.

3) Abalovich M, Gutierrez S, Alcaraz G, Maccallini G, Garcia A, Levalle O. Overt and subclinical hypothyroidism complicating pregnancy. Thyroid 2002;12(1):63-8.

4) Karakosta P, Alegakis D, Georgiou V, Roumeliotaki $T$, Fthenou E, Vassilaki M, et al. Thyroid dysfunction and autoantibodies in early pregnancy are associated with increased risk of gestational diabetes and adverse birth outcomes. J Clin Endocrinol Metab 2012;97(12):4464-72.

5) Tudela CM, Casey BM, McIntire DD, Cunningham FG. Relationship of subclinical thyroid disease to the incidence of gestational diabetes. Obstet Gynecol 2012;119(5):983-8.

6) Stohl HE, Ouzounian J, Rick AM, Hueppchen NA, Bienstock JL. Thyroid disease and gestational diabetes mellitus $(G D M):$ is there a connection? J Matern Fetal Neonatal Med 2013;26(11):1139-42.

7) Gorar S, Abanonu GB, Uysal A, Erol O, Unal A, Uyar S, et al. Comparison of thyroid function tests and blood count in pregnant women with versus without gestational diabetes mellitus. J Obstet Gynaecol Res 2017;43(5):848-54.

8) Agarwal MM, Dhatt GS, Punnose J, Bishawi B, Zayed R. Thyroid function abnormalities and antithyroid antibody prevalence in pregnant women at high risk for gestational diabetes mellitus. Gynecol Endocrinol 2006;22(5):261-6.

9) Mannisto T, Vaarasmaki M, Pouta A, Hartikainen AL, Ruokonen A, Surcel HM, et al. Thyroid dysfunction and autoantibodies during pregnancy as predictive factors of pregnancy complications and maternal morbidity in later life. J Clin Endocrinol Metab 2010;95(3):1084-94.

10) Haddow JE, Craig WY, Neveux LM, Palomaki GE, Lambert-Messerlian G, Malone FD, et al. Free thyroxine during early pregnancy and risk for gestational diabetes. PLoS One 2016;11(2):e0149065.

11) Yang S, Shi FT, Leung PC, Huang HF, Fan J. Low thyroid hormone in early pregnancy is associated with an increased risk of gestational diabetes mellitus. J Clin Endocrinol Metab 2016;101(11):4237-43.

12) Stagnaro-Green A, Abalovich $M$, Alexander E, Azizi F, Mestman J, Negro R, et al. Guidelines of the American Thyroid Association for the diagnosis and management of thyroid disease during pregnancy and postpartum. Thyroid 2011;21(10):1081125.

13) Alexander EK, Pearce EN, Brent GA, Brown RS, Chen H, Dosiou C, et al. 2017 Guidelines of the American Thyroid Association for the diagnosis and management of thyroid disease during pregnancy and the postpartum. Thyroid 2017;27(3):31589.

14) Toulis KA, Stagnaro-Green A, Negro R. Maternal subclinical hypothyroidsm and gestational diabetes mellitus: a meta-analysis. Endocr Pract 2014;20(7):703-14.

15) Das DK, Bandyopadhyay D, Bandyopadhyay S, Neogi A. Thyroid hormone regulation of beta-adrenergic receptors and catecholamine sensitive adenylate cyclase in foetal heart. Acta Endocrinol (Copenh) 1984;106(4):569-76.

16) Furukawa S, Miyakawa K, Shibata J, Iwashita M. Women 
Antenatal Thyroid Function and GDM Risk

with subclinical hypothyroidism are at low risk of poor pregnancy outcome in Japan. Tohoku J Exp Med 2017;242(3):167-72.

17) Ying H, Tang YP, Bao YR, Su XJ, Cai X, Li YH, et al. Maternal TSH level and TPOAb status in early pregnancy and their relationship to the risk of gestational diabetes mellitus. Endocrine 2016;54(3):742-50.

18) Rawal S, Tsai MY, Hinkle SN, Zhu Y, Bao W, Lin Y, et al. A longitudinal study of thyroid markers across pregnancy and the risk of gestational diabetes. I Clin Endocrinol Metab 2018;103(7):2447-56.

19) Casey BM, Dashe JS, Spong CY, McIntire DD, Leveno KJ, Cunningham GF. Perinatal significance of isolated maternal hypothyroxinemia identified in the first half of pregnancy. Obstet Gynecol 2007;109(5):1129-35. 